\title{
Liquefied Natural Gas for Trucks and Buses
}

\author{
James Wegrzyn \\ Brookhaven National Lab \\ Michael Gurevich \\ U.S. Dept. of Energy
}


SAE routinely stocks printed papers for a period of three years following date of publication. Direct your orders to SAE Customer Sales and Satisfaction Department.

Quantity reprint rates can be obtained from the Customer Sales and Satisfaction Department.

To request permission to reprint a technical paper or permission to use copyrighted SAE publications in other works, contact the SAE Publications Group.

This article was prepared as an account of work sponsored by an agency of the United States

Government. Neither the United States Government nor any agency thereof, nor any of their employees, makes any warranty, express or implied, or assumes any legal liability or responsibility for the accuracy, completeness, or usefulness of any information, apparatus, product, or process disclosed, or represents that its use would not infringe privately owned rights. Reference herein to any specific commercial product, process, or service by trade name, trademark, manufacturer, or otherwise does not necessarily constitute or imply its endorsement, recommendation, or favoring by the United States Government or any agency thereof. The views and opinions of authors expressed herein do not necessarily state or reflect those of the United States Government or any agency thereof.

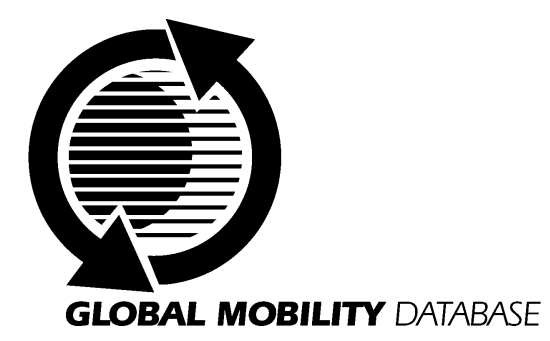

All SAE papers, standards, and selected books are abstracted and indexed in the Global Mobility Database

ISSN 0148-7191

No copyright is asserted in the works of U.S. Government employees.

Positions and opinions advanced in this paper are those of the author(s) and not necessarily those of SAE. The author is solely responsible for the content of the paper. A process is available by which discussions will be printed with the paper if it is published in SAE Transactions. For permission to publish this paper in full or in part, contact the SAE Publications Group.

Persons wishing to submit papers to be considered for presentation or publication through SAE should send the manuscript or a 300 word abstract of a proposed manuscript to: Secretary, Engineering Meetings Board, SAE.

\section{Printed in USA}




\title{
Liquefied Natural Gas for Trucks and Buses
}

\author{
James Wegrzyn \\ Brookhaven National Lab \\ Michael Gurevich \\ U.S. Dept. of Energy
}

No copyright is asserted in the works of U.S. Government employees

\begin{abstract}
Liquefied natural gas (LNG) is being developed as a heavy vehicle fuel. The reason for developing $L N G$ is to reduce our dependency on imported oil by eliminating technical and costs barriers associated with its usage. The U.S. Department of Energy (DOE) has a program, currently in its third year, to develop and advance costeffective technologies for operating and refueling natural gas-fueled heavy vehicles (Class 7-8 trucks). The objectives of the DOE Natural Gas Vehicle Systems Program are to achieve market penetration by reducing vehicle conversion and fuel costs, to increase consumer acceptance by improving the reliability and efficiency, and to improve air quality by reducing tailpipe emissions. One way to reduce fuel costs is to develop new supplies of cheap natural gas. Significant progress is being made towards developing more energy-efficient, low-cost, small-scale natural gas liquefiers for exploiting alternative sources of natural gas such as from landfill and remote gas sites. In particular, the DOE program provides funds for research and development in the areas of; natural gas clean up, LNG production, advanced vehicle onboard storage tanks, improved fuel delivery systems and LNG market strategies. In general, the program seeks to integrate the individual components being developed into complete systems, and then demonstrate the technology to establish technical and economic feasibility. The paper also reviews the importance of cryogenics in designing LNG fuel delivery systems.
\end{abstract}

\section{BACKGROUND}

The past twenty-five years saw truck traffic as being accountable for large increases in the annual fuel consumption within the transportation energy sector. This large movement of goods by heavy vehicles is directly related to the healthy growth of the national economy. In order to meet the growing needs of the trucking industry and stricter clean air requirements, the Department of
Energy - Office of Heavy Vehicle Technologies (DOEOHVT) has undertaken an R\&D program to develop fuel efficient, low-emissions trucks. Under the Natural Gas Vehicle Systems Program support is provided in developing liquefied natural gas technologies in the areas of production, storage tanks and refueling systems [1,2]. Specific program goals include the following: (1) eliminating evaporative greenhouse gas emissions; (2) recovering $25 \%$ of the energy of liquefying and transporting natural gas; and (3) increasing onboard fuel storage capacity by $40 \%$ for compressed natural gas (CNG) and $25 \%$ for LNG. The contracts for this program are administered from the DOE-Argonne Operations Office with Brookhaven National Laboratory (BNL) providing technical assistance.

In addition to the DOE programs, others have explored the uses of $L N G$ as a fuel for heavy vehicles. However, in many of the early LNG test problems were encountered with the onboard pressure management and fuel delivery systems. Excessive venting of LNG resulted in fluctuations of fuel flow and changing fuel composition to the engine. Fluctuations in fuel flow and energy content were suspected as being the causes of some engine damage. Unfortunately, these same issues, which affect engine performance, are still troubling us today. For example, a 1996 report by the Maryland Transit Administration [3] identified several problems with the handling and storage of LNG as a fuel for transit buses. This report cited "decreased reliability and increased maintenance costs for LNG coaches may be directly related to current LNG fuel delivery systems." Even more recently, the Dallas Area Rapid Transit (DART) reports excessive venting and partial or incomplete fills as reasons for possible delaying or postponing their planned expansion of their LNG fleet. There are, on the other hand, examples of where LNG as a heavy vehicle fuel has been a success. The Idaho National Engineering and Environmental Laboratory (INEL) [4] for years has been safely and routinely operating a fleet of LNG transit buses. 


\section{FUEL DELIVERY SYSTEMS}

LNG as a transportation fuel has been the subject of several studies [5-8]. The two types of LNG fuel delivery systems being looked at in this paper are the vapor collapse (saturated) system and the vapor return system. Figure 1 shows the general features of a vapor collapse system. Figure 2 illustrates the vapor return system. The distinctions between these two approaches to fuel delivery are best discussed by looking at the operation of the onboard LNG storage tank. The LNG fuel tank for the vapor collapse system requires only a single line connector from the refueling station. By spraying cold LNG into the tank, the temperature of the residue vapor in the tank can be lowered until the vapor condenses (collapses) into its liquid state. This reduces the pressure in the onboard tank allowing it to be refueled. The tank is then filled with LNG up to its operating pressure. On the other hand with the vapor return system, LNG is directly pumped as a sub-cooled liquid rather than a saturated fluid. The vapor, which is being displaced, is returned through a second line. Tables I and II summarize the advantages and some of the disadvantages of each system. A very significant difference between these two fuel delivery systems is in the way in which the pressures of the onboard fuel tanks are controlled. In the vapor collapse system, the LNG tanks are designed with a moderate heat leak rate (40 BTU/HR) or $2 \mathrm{BTU} / \mathrm{HR}$-FT2 for an 18-inch diameter tank. This heat input continually raises the vapor pressure within the fuel tanks. The economizer valves control the pressure by releasing vapor to the engine's fuel supply line whenever the tank's pressure exceeds its set point. An economizer valve is essentially a check valve and pressure regulator.

The onboard tanks in the vapor return system have a relatively low heat leak rate $(10 \mathrm{BTU} / \mathrm{HR})$. Only liquid is withdrawn from these tanks, eliminating the need for economizer valves. The low heat leak rate permits holdtimes of up to seven days before vapor release will occur. These types of tanks, however, do require a secondary pressure-build device or an onboard pump to supply the engine with fuel if pressures of 75 psig or greater are needed. The pressure-build device extracts and vaporizes a small quantity of liquid from the tank and then returns it to the same tank as a super heated vapor. Once the tank is at its operating pressure with this false pressure head of methane vapor, the tank's pressure remains fairly constant over the vehicle's driving cycle. It should be noted that care must be taken to prevent vapor pressure collapse when using a false pressure head since the vapor is not in equilibrium.

Figures 1 and 2 highlight the basic parts of the LNG fuel delivery system. The function of the system is to; load 25 psig LNG at a production site, transfer it usually by a (35 psig) tanker truck to a (50-60 psig) refueling station, refuel vehicles up to a tank pressure of $150 \mathrm{psig}$, and then have the onboard storage tanks supply the engine with a "controlled amount" of fuel. This needs to be accomplished without venting any natural gas, without changing the LNG composition, and with accurate metering. The problem is that since the LNG is kept at cryogenic temperatures heat is continually leaking into the system. The rate of this heat leak causes venting (losses to the atmosphere), weathering (changes in LNG composition with time) and variations in fluid densities.

Table I. Vapor Collapse Delivery System

Vapor Collapse Delivery System
Advantages
- $\quad$ Single line fill
- $\quad$ No onboard pressure build device
- $\quad$ Higher heat leak rates tolerated
Disadvantages
- $\quad$ Lower onboard fuel density storage
- $\quad$ Connectors are at higher pressures
- $\quad$ Susceptible to venting
- $\quad$ Susceptible to weathering
- $\quad$ Requires an economizer valve
- $\quad$ Can experience large pressure changes
- $\quad$ between engine and tank
- $\quad$ tanks
Can experience incomplete refill

Table II. Vapor Return Delivery System

Vapor Return Delivery System
Advantages
- $\quad$ Higher onboard fuel density storage
- $\quad$ Connectors are at lower pressures
- $\quad$ No weathering problems
- $\quad$ Uniform pressure drop between tank and engine
- $\quad$ No economizer valve
- $\quad$ Compatible with second stage heat exchanger
- $\quad$ Complete refill
Disadvantages
- $\quad$ Two line connection
- $\quad$ Requires either onsite liquefaction or access to
- pipeline
Requires an onboard pressure build
- $\quad$ Ponditioning) device or pump
- Requires a very low heat leak rate tank




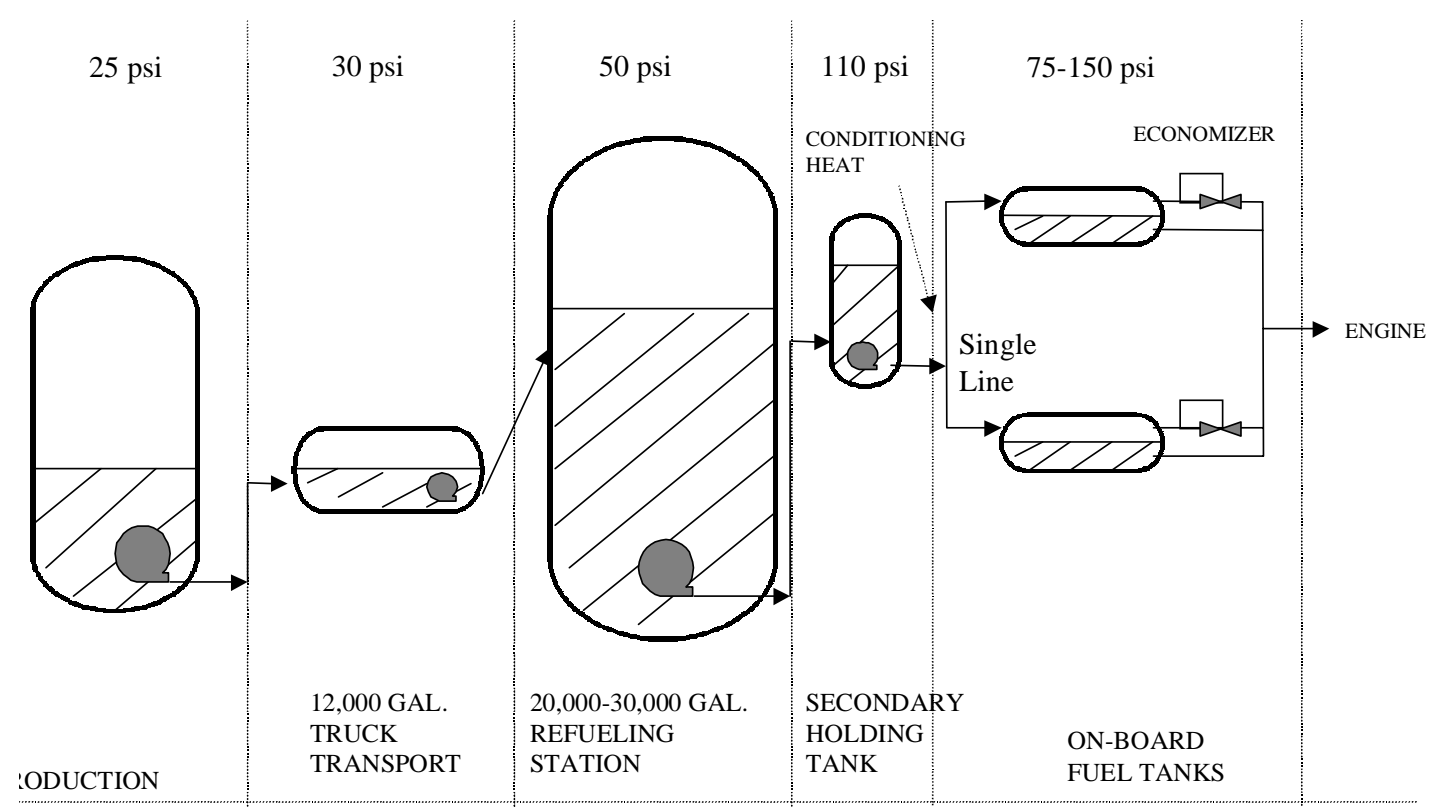

Figure 1. Vapor Collapse System

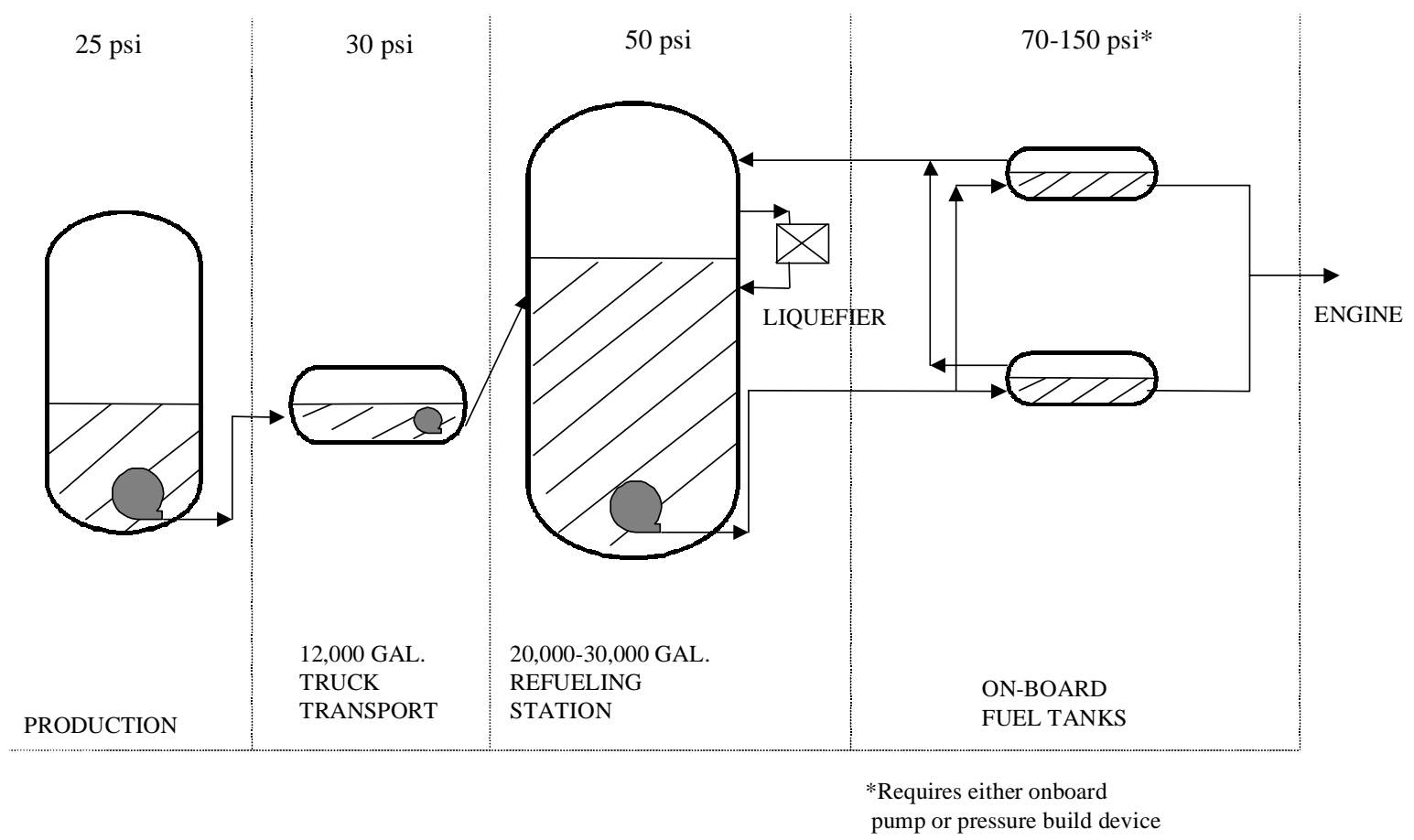

Figure 2. Vapor Return System

The cradle to grave handling of LNG is challenging, but a criteria for a properly designed fuel delivery system simply stated is, "The on site fueling station must be in total concert with the on board vehicle fuel system" (5). In other words the fuel pressure needs of the engine and the type of fuel tank (vapor collapse or vapor return) impact directly the design and operation of the LNG refueling station. The 75 to 150 psig pressures for onboard tanks indicated in figures 1 and 2 come from the fact that different natural gas engines having different fuel supply pressure needs. A LNG transfer pump can build a pres- sure head of around 60 psig. The term given to the practice of intentionally adding heat to raise system pressure is called "conditioning". When using the vapor collapse type of on board fuel tank, refueling a 150 psig vehicle fuel tank from a 50-psig tank usually involves a conditioning tank as well as a transfer pump. Refueling a 75 psig vehicle fuel tank from a 50-psig tank is possible with a transfer pump alone. The point is that the station operator needs to know the vehicle's fuel delivery system in order to properly refuel the vehicle. This is not the case for the vapor return system, where the fuel is pumped on 
board at pressures slightly above the saturated pressure of the refueling station. As discussed earlier the fuel tank's pressure is then raised to the tanks operating pressure with an on board pressure build device. During the pressure build cycle the vehicle is operational but not at full throttle. The time to build the pressure can be up to ten minutes.

These figures also indicate that multiple on board tanks are required to get the necessary amount of fuel on board. Trucks carry two 110-gal tanks while buses have either three or four 60-gal tanks. Unfortunately multiple tanks complicate both refueling and withdrawing of LNG. This is especially true for the vapor collapse system as Table I has indicated. With the vapor return system the tanks can be refueled in series with the over flow going to the next tank. The obvious question is; what to do with the returned vapor, since venting is not an option. One solution is to heat it back to ambient conditions and odorize it so it can be placed back into a natural gas pipeline. If the price of electricity is high then it could be used as fuel to produce electricity. Another option, which is shown in Figure 2, is to return the vapor back to the 20,000-30,000 gallon tank at the refueling station. Since this will add heat to the tank an on-site liquefier would be required to keep the $20,000-30,000$ gallon tank in thermal balance.

\section{LNG FUEL DELIVERY COMPONENTS}

The DOE-OHVT Natural Gas Vehicle Systems Program has several projects (Lone Star, Beck, IGT, CVI, ATM and Snyder/BorgWarner) to develop components for fuel delivery systems. This paper will highlight some of the accomplishments of these projects as they relate to LNG fuel delivery.

Advanced Technologies Management, Inc. of Cleveland, Ohio, is contracted to develop a second-stage intercooler for turbo-charged heavy vehicles. It is well known that by reducing the engine's inlet air temperature the engine's power output can be increased and nitrogen oxides (NOx) emissions can be reduced. The project consists of testing a simple unitary design of a heat exchanger that uses the vehicle's air conditioning coolant (R 22) as the heat transfer fluid between the LNG, which is vaporized, and the inlet air. The objectives are to achieve a $20 \%$ increase in power output with a $10 \%$ reduction in NOx. Previous tests have shown that with a $50^{\circ} \mathrm{F}$ reduction in the engine's manifold temperature the NOx emissions can be significantly reduced. The $20 \%$ power boost will require not only low air inlet temperatures but also optimization of air/fuel ratio, turbo charger and timing.

Beck Engineering of Gig Harbor, Washington, is developing for DOE-OHVT a 1 kilowatt (1.34 hp), free piston (20 $\mathrm{gm} / \mathrm{sec}$ ), cryogenic, natural gas pump. Two prototypes are under development including a medium pressure (200 psig) pump that could replace the pressure build device, and a high pressure (3000 psig) pump that would be required for all high-pressure direct-injected natural gas engines. The targeted purchase price of these pumps, which will depend on production volume, is between $\$ 500$ to $\$ 1000$ dollars. A novel feature of these pumps is the free-piston variable displacement design, which makes it insensitive to cavitation. The magnetically driven piston can be hermetically sealed. This feature reduces heat leaks and limits vapor formation. The pump has been tested for proof-of- concept and work is now being done on minimizing electrical and mechanical energy losses. Integration of the pump into an on-board vehicle LNG fuel delivery system will then follow. Under a separate DOE-OHVT Small Business Innovation Research (SBIR) project, The Research Partnership (TRP) of Palo Alto, California, is teamed with Westport Innovations of Vancouver, British Columbia, to develop a LNG vehicle high-pressure fuel system using a lowspeed reciprocating pump mounted external to a relatively conventional LNG fuel. An initial version of this pump is being installed in Class 8 trucks powered by Cummins ISX engines with Westport's High-Pressure Direct Injection (HPDI) system. These trucks, which use a hydraulic fuel pump drive, will be demonstrated in California and British Columbia [9]. TRP is developing an advanced pump drive system, which derives power from the vaporizing LNG so that no engine attachments or power consumption is needed [10].

Lone Star Energy Co. of Dallas, Texas is under contract with the DOE-OHVT to advance the development of the L/CNG fueling station. With this type of station one can refuel both CNG as well as LNG vehicles at the same site. L/CNG stations have lower capital and operating costs than a similarly sized CNG station [11]. Therefore, L/CNG stations are sometimes used to fill only CNG vehicles. The L/CNG station uses a high pressure-reciprocating pump to pressurize the LNG to over 4000-psig. This high-pressure natural gas is then vaporized to supply CNG. This approach eliminates the need for expensive gas compressors. Lone Star is documenting the facility costs for both $L N G$ and L/CNG stations. This work includes actual cost from associated with planning, permitting and construction, as well as operational and maintenance costs. Lone Star is also working on improving the current L/CNG station design to improve safety, convenience, flexibility and user friendly operation.

CVI (Chart Industries) of Columbus, Ohio is a manufacturer of L/CNG stations. Under contract to DOE-OHVT they modified an existing LNG station to also refuel CNG vehicles. This was accomplished by installing a highpressure pump in the refueling station main LNG storage tank. Controls, fuel dispenser and odorant were also installed. In another project but not funded by DOEOHVT, CVI installed a pair of 200-watt Gifford-McMahon refrigerators at the top of a 25,000-gal LNG storage tank. This effectively eliminated boil off and kept the tank pressure at a constant 60 psig despite a $600 \mathrm{BTU} / \mathrm{HR}$ heat leak rate. To the author's knowledge this is the first attempt to control boil off with an on site liquefier. This concept can be expanded to include re-liquefying return vapor from the vehicles fuel tanks. 
With support from DOE-OHVT, Snyder/ Borg-Warner has developed LNG fuel tanks for Class $7 \& 8$ trucks and transit buses. These tanks have the very low heat leak rate of $10 \mathrm{BTU} / \mathrm{HR}$. These tanks have been designed with a central support beam made of composite materials which minimizes the conductive heat losses between the outer tank shell and the inner vessel. With a high vacuum insulation these tanks show a 4 to 1 improvement in thermal performance compared with current, commercially available tanks. With this design economizer valves are not needed to control pressure build-up in the tanks. Only liquid is drawn from the tank to fuel the engine. The liquid feed to the vaporizer eliminates many of the problems associated with controlling fuel flow and fuel quality to the engine. The price for this tank is estimated to be $\$ 7,000$. This tank design does require a return line during refueling. As discussed in the previous section the returned LNG vapor can be introduced into a gas pipeline. Another option (if the station is not close to a pipeline) is to return the vapor to the main LNG storage tank of the refueling station. This introduces an additional heat load to the station's LNG storage tank, which would then require an on-site liquefier.

The Institute of Gas Technology (IGT) of Des Plaines, IL, is developing for DOE, a small-scale LNG liquefier [12] that is low-cost and energy-efficient, and could serve as an on- site liquefier for recovering LNG vapor that is returned from the vehicle. IGT's design is based on a mixed-refrigerant system and uses commercially available compressors and heat exchanger. The pilot system has been tested to provide 300 gallons of LNG per day. At this capacity the unit is appropriate for on- site liquefying of $L N G$ vapor at the refueling station. The cost of liquefaction is estimated to be less than seven cents per gallon of LNG. The cost of the liquefier consists mainly of the screw compressor (Carlyle) at $\$ 5,000$, and the heat exchanger (Altec) at $\$ 30,000$.

With advancements in small-scale liquefiers for those applications where LNG is to be produced from unconventional sources, such as landfill gas, there is now an even greater interest in developing cost-effective gas purification technologies. Acrion Technologies has developed a process for removing contaminants from landfill gas and producing liquid carbon dioxide $\left(\mathrm{CO}_{2}\right)$ and methane. The patented process uses liquid $\mathrm{CO}_{2}$ produced on-site to absorb the contaminants. The process can wash 2-5 million standard cubic feet (MMSCF) of raw landfill gas to produce up to 21,000 gallon of LNG per day and 70 tons of $\mathrm{CO}_{2}$ per day. With revenue generated from the sale of these products, at $\$ 0.40 /$ gallon for $\mathrm{LNG}$ and $\$ 40$ /ton for liquid $\mathrm{CO}_{2}$, the production cost of LNG is estimated to be 10 cents per gallon. Under a separate DOE contract Acrion is now building a demonstration unit that could supply 1,800 gallons of LNG per day from landfill gas. This can easily fuel a fleet of 15-20 trash vehicles.

\section{DISCUSSION}

There are other elements to the DOE OHVT Natural Gas Vehicle Systems program besides fuel delivery. Two field demonstration projects are being actively pursued. The first, is a project to recover methane to produce LNG from landfill gas for refueling onsite, refuse trucks. The capability to produce LNG onsite for immediate use has the advantage that some infrastructure transportation cost is avoided. That is the cost of transporting the fuel from another source is eliminated. The landfill operator has a secured source of fuel with some road tax avoidance. The second project demonstrates production of LNG from a remote gas well. Both projects require small-scale liquefiers and gas pretreatment systems.

Weathering, metering, and fueling connectors are all topics associated with LNG systems. The LNG fueling connectors that are currently being sold are expensive. The high purchase price is due mainly to the limited demand for these types of connections. There are also reported field problems with leakage during refueling with these connectors. The Natural Gas Vehicle Coalition (NGVC) and the Society Automotive Engineers (SAE) are reviewing standardization of connectors and fittings.

Weathering [12] is the term used to describe the change of $L N G$ composition with time. LNG is a mixture of fluids consisting primarily of methane and other trace alkanes such as ethane, propane, and butane. Unlike diesel or gasoline the make-up of LNG is continually changing as heat enters the system and methane is preferentially vaporized over the other alkanes. The removal of methane vapor will enrich the remaining LNG liquid with ethane, propane, etc. Methane has an octane number of about 140; while enriched LNG has an octane number of about 134. The concern is about potential engine damage and tail pipe emissions with this variability in fuel quality. As discussed in this paper this variability can be caused through the delivery and storage of LNG. The NGVC is working with the SAE on this issue and has a working committee in place. One suggested practice [57] has been to use only high purity LNG, greater than $98 \%$ methane. With this approach weathering of the fuel is not a problem. High purity LNG is readily available at large gas processing plants. However producing high purity LNG at peak-shaving plants or from small-scale liquefiers located at remote gas sites add an additional cost of around $\$ 0.10$ per gal. Studies are under way to help identify the difference in cost between transporting high purity LNG from distant gas processing plants; to producing $90-96 \%$ LNG on or near where it is to be used.

Metering will become increasingly important as the LNG market grows. The tanker load today buys most LNG, so accurate metering between the vehicle and the station is not needed. But as LNG usage moves from the captive fleet market to the public market accurate metering will 
become a must. Again the NGVC and SAE have a working committee on this subject. In closing, the pathways (choices) for introducing LNG technology into the heavy vehicle market are many. But if this technology is to have an impact, understanding the basic cryogenic nature of, and the correct handling procedures for LNG is critical.

\section{ACKNOWLEDGEMENTS}

This work was done under contract no. DE-AC02$98 \mathrm{CH} 10886$ with the United States Department of Energy.

\section{REFERENCES}

1. Wegrzyn, J., et.al., "DOE/BNL Liquid Natural Gas Heavy Vehicle Program," Future Transportation Technology Conference, Costa Mesa, CA, August 11-13, 1998, SAE Paper No. 981919.

2. Wegrzyn, J., et. al., "Natural Gas as a Fuel Option for Heavy Vehicles," SAE Government/Industry Meeting, Washington, D.C., April 26-28, 1999, SAE Paper No. 1999-01-2248.

3. "The Maryland Mass Transit Administration Demonstration of Liquefied Natural Gas Buses," Final Report, prepared for Maryland Transit Admin., October 18, 1996.

4. Siu, N., Herring, et.al., "Interim Qualitative Risk Assessment for an LNG Refueling Station and Review of Relevant Safety Issues," Idaho National Engineering Laboratory, Report No. INEEL/EXT-9700827, July 1997.
5. Hanshaw, G., Pope, G., "Fuel Quality Recommendations for Natural Gas Vehicular Fuel," SAE International Truck \& Bus Meeting, Seattle, WA, November 7-9, 1994, SAE Paper No. 942313.

6. Hanshaw, G., Pope, G., "Liquefied Natural Gas Heavy Duty Truck Applications," SAE Paper No. 952740.

7. Hanshaw, G., Pope, G., "Liquefied Natural Gas Criteria/Comparative Values for Use as an Automotive Fuel," SAE International Spring Fuels \& Lubrication Meeting, Dearborn, MI, May 6-8, 1996, SAE Paper No. 961178.

8. "LNG Weathering Effects- Theoretical and Empirical," prepared for Gas Research Institute (GRI) by Southwest Research Institute, GRI Report No. GRI92/0464, December 1992.

9. "Westport Innovations Set to Demonstrate Natural Gas Technology", Diesel Progress, North American Edition, March 2000.

10. Powars, C. and Derbidge, T. "Liquefaction Energy Recovery in LNG and LH2 Fueled Vehicles", to be presented at the SAE International Future Transportation Meeting, Costa Mesa, California, CA, August 2000.

11. "LNG Vehicle Markets and Infrastructure," prepared for Gas Research Institute by Zeus Development Corp., March 1998.

12. Kountz, K., "Status of DOE's Single Stage, Mixed Refrigerant, LNG Liquefier Project," Institute of Gas Technology Project Report.

13. Kountz, K., "Weathering Tests in LNG Tanks," Institute of Gas Technology Topical Report, May 1999. 